Dept. of Surgery, Faculty of Veterinary Medicine, Assiut University.

\title{
CLOSURE OF CYSTOTOMY IN DOGS USING DIFFERENT TYPES OF SUTURE MATERIALS AND TISSUE ADHESIVE
}

(With 12 Figures)

By

M.T. NASSEF; M.A. ALI; A. NAFADY and A.F. GALAL (Received at 8/4/2010)

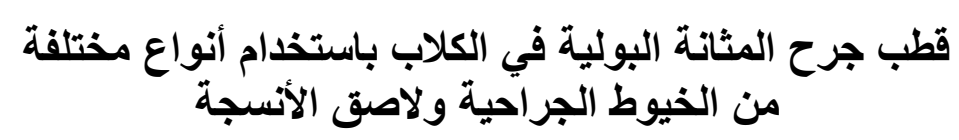

محمد طنطاوي ناصف ، محمد عادل محد ، علام عبل الحمبا نفادى ، احد

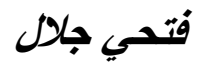

أجريت هذه الدر اسة على عدد72 من الكلاب البالغة بين الذكور والإناث. وقسمت هذه الحيو انات

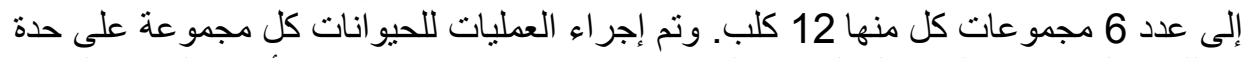

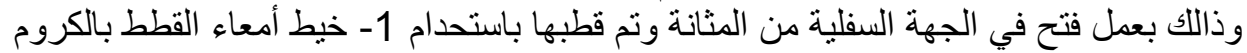

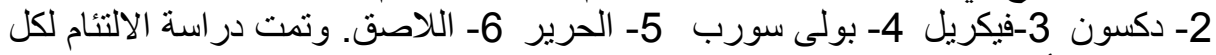

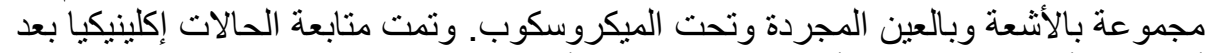

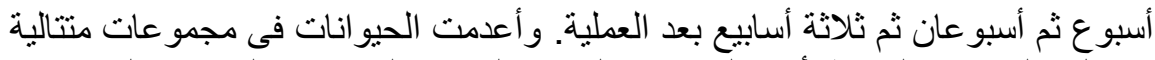

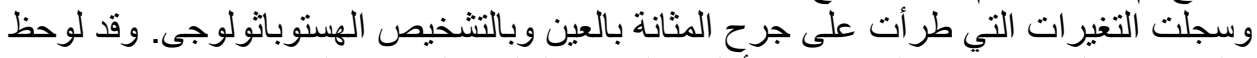

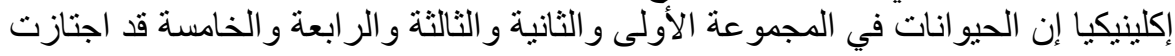

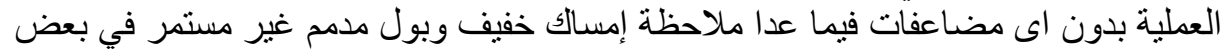

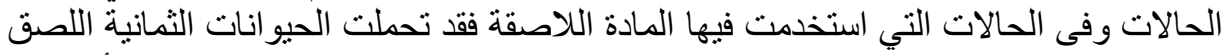

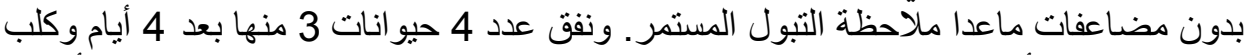

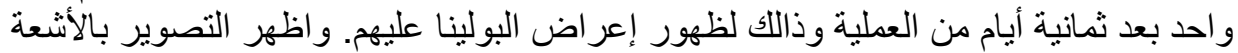

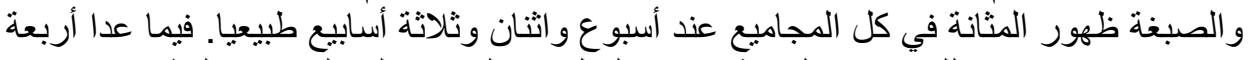

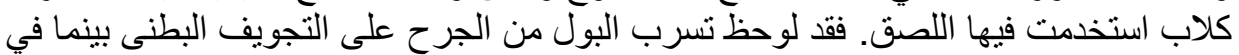

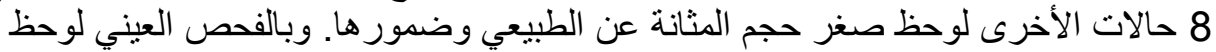

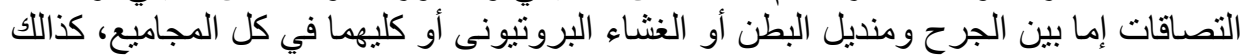

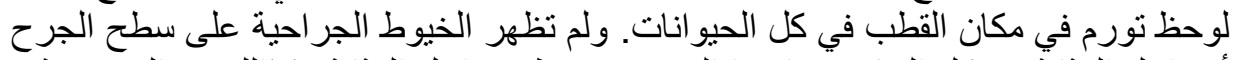

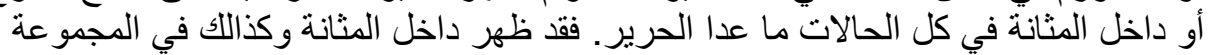

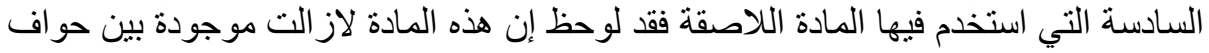

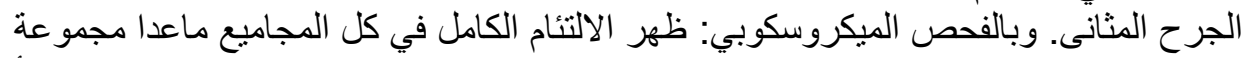

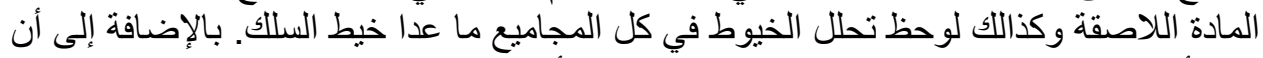
خيط أمعاء القطط لاز ال يحتفظ بخو اصله حتى نهاية الأسبو عل الثئ الثالث. 


\section{SUMMARY}

Experimental ventral cystotomy wounds were performed on 72 adult dogs of different sex and age. Cystotomy wound was closed by chromic catgut, polyglycolic acid, vicryl, Polysorb, silk and methyl-2-Cyanoacrylate super glue. Animals were sacrificed at one, two and three weeks postoperatively, and site of operation were examined grossly, microscopically and by scanning electron microscopy. The results of this study reconfirms that catgut is the best thread used for suturing of the urinary bladder incisions. Polyglycolic acid, vicryl and Polysorb were hydrolyzed and they are not sufficient for suitable time for healing of wound. Silk not absorbed and can cause the nidus for urinary calculi. Non absorbable tissue adhesives were unsuitable for urinary bladder closure, because there is no healing at the site of operation and lead to deformity and shrinkage of the bladder wound.

Key wards: Urinary bladder, cystotomy, Suture materials, Tissue adhesives, Dog.

\section{INTRODUCTION}

The need for opening or removing part of the urinary bladder arises frequently. However, complications may accompany its suture closure. Leakage considers the most important one of them. Many suture materials, tissue adhesives and techniques were renewed and applied for successful closure of different tissues and organs (Samy, Bolbol, Bayoumy and Moustafa, 1986).

At present, there are no clear guidelines for the most suitable suture materials available for the closure of urinary bladder defects. The general tendency is to use synthetic absorbable suture materials. The fluid nature of its contents, with a high concentration of solutes, predisposes to both a susceptibility to infection and a propensity to form concretions. It is now accepted in practice that only absorbable suture material should be used to repair bladder wall defects, although monofilament non absorbable suture could be used in urological procedures. (Pal, 1998).

Cyanoacrylate was discovered in 1940; it has been evaluated as a potential tissue adhesive. Earlier forms of cyanoacrylate caused extensive tissue reaction, and thus could not be used as a tissue adhesive. Over time more stable forms of the compound were developed, and now Dermabond topical skin adhesive (formulated 2-octylcyanoacrylate) is currently approved for topical use to hold closed easily approximated skin lacerations. Because of the previous concerns about tissue reaction, as well 
as some concerns over the potential carcinogenicity of the earlier compounds, cyanoacrylate adhesives have not yet been approved for internal use. These earlier forms of cyanoacrylate were non-absorbable, and moreover, were purported to be carcinogenic. (Giunta and Shklar, 1972; Vinters, Galil, Lundie and Kaufmann, 1985; Switzer, Dinsmore and North, 2003).

\section{MATERIALS and METHODS}

The present study was carried out on 72 apparantly healthy mongrel adult dogs (males and females). All animals were subjected to ventral cystotomy followed by cystorrhaphy. The animal was premedicated using (chlorpromazine HCL) and anaesthetized by Thiopental sodium. According to the type of suture materials used for cystorrhaphy, the animals were classified into six groups each of $12 \mathrm{dogs}$, and then the incision was closed using chromic catgut $2 / 0$ in group (1), dexon $2 / 0$ in group (2), vicryl $2 / 0$ in group (3), polysorb $2 / 0$ in group (4), silk $2 / 0$ in group (5) and tissue adhesive in group (6). The cystotomy incision $(5-7 \mathrm{~cm}$ long) was made on the ventral aspect of the urinary bladder. The incision was closed using the different suture materials in the form of two layer suture, the mucosa was sutured with interrupted horizontal mattress everting sutures. The submucosa, tunica muscularis and serosa were closed by one-layer-inverting Cushing sutures. In group (6) methyl-2-Cyanoacrylate super glue was used, a small amount of the adhesive material was spread over the wound edges with the aid of a small brush, one on the mucosa and the other one on sero-muscular layer.

Following operation, animals were maintained under controlled laboratory conditions. At periods of one, two and three weeks, all dogs were subjected to radiographic examination. The dogs were euthanized by Thiopental sodium and the bladder was carefully examined grossly then excised, and processed for routine histologic examination and cytologic evaluation by electron microscopy.

\section{RESULTS}

All animals in group1, 2,3,4,5 survived the study without any complications except mild constipation and hematurea which did not continued more than four days. In case of group(6), eight dogs survived the study without complication except frequent urination. There are four animals was died after four ( $3 \mathrm{dogs})$ and eight ( $1 \mathrm{dog}$ ) days postoperatively suffering from signs of uremia. 
Radiographically, The urinary bladder appeared normal in all groups at 1,2 and 3 weeks postoperatively, without any deformity or leakage of urine. But in case of group (6) four cases showed leakage of urine into abdominal cavity. While in the other eight cases the urinary bladder was observed smaller than normal, shrinked and contracted with deformity in its outline surface mainly at the site of tissue adhesive.

Macroscopically, There were variable degrees of adhesions (mild, moderate and severe) at 1,2 and 3 weeks in all groups. The adhesions were omental adhesions in 32 cases, omento-peritoneal adhesions in 28 cases and peritoneal adhesions only in 8 cases. These adhesions were observed through the whole length of the suture line on the ventral surface of urinary bladder or just including part from it. In all animals the suture lines appeared hard in consistency with mild swelling. The suture material in group 1, 2, 3 and 4 was not observed from serosal or mucosal surface, except in cases of group 5, the silk suture appeared from mucosal surface with blackish colouration. In group 6, the tissue adhesive was lodged between wound edges and could be detected from mucosal and serosal surfaces.

Microscopically, the suture line showed complete healing in group $1,2,3,4$ and 5, with regenerating transitional epithelium. In case of group (6), there was no healing in the mucosal and muscular layer, but there was partial healing with fibrous connective tissue in the serosal layer. The suture material was observed in all groups at 1, 2, 3 weeks postoperatively. In case of catgut group, the suture material appeared contracted and shrinked mainly at $3^{\text {rd }}$ week, and was surrounded by polymorph nuclear cells. In case of group 2, 3 and 4 the suture material was present with variable degree of hydrolysis mainly at $3^{\text {rd }}$ week postoperatively. The suture material was surrounded by heavy leukocytic and fibroblastic cell proliferation with some macrophages and RBC. In case of group (4), there were some areas showing deposition of calcium. In case of group (5) silk was observed along the study without any change in its position and was surrounded by RBC and leukocytic cell infiltration with formation of pockets or cysts in the mucosa which may act as a nidus for stone formation. In case of group(6), the adhesive material could be observed grossly. Scanning electron microscope showed it as irregular mass filling the gap between the wound edges. It was surrounded by leukocytic and fibriblastic cell reaction.
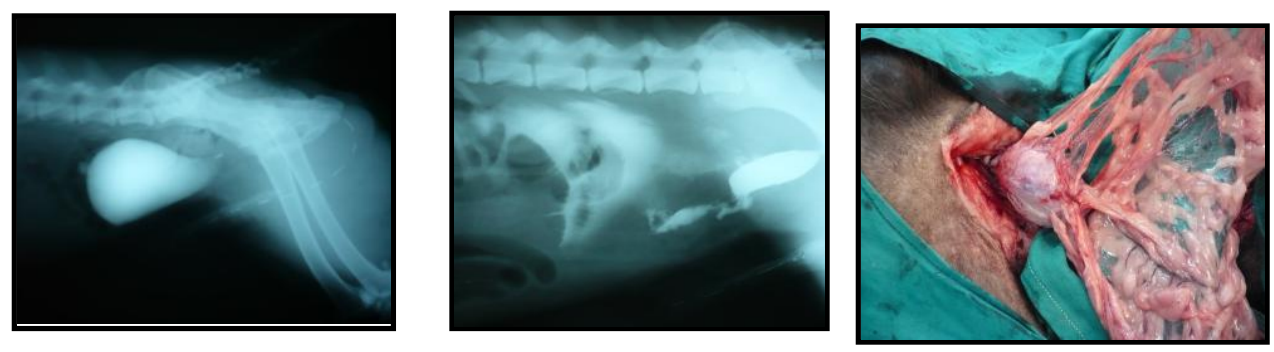
Fig (1)

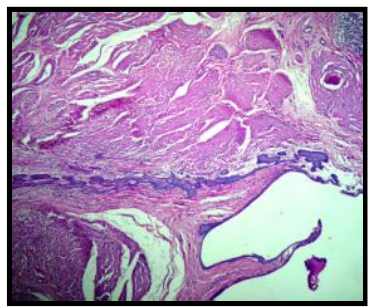

Fig (4)

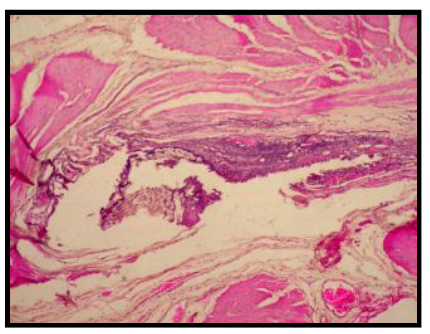

Fig (7)

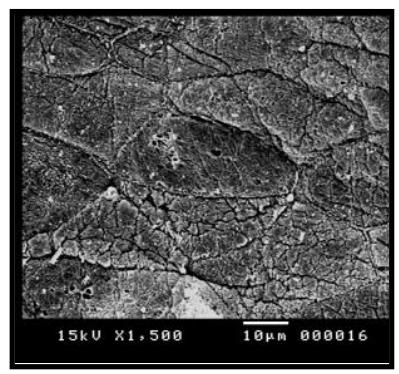

Fig (10)
Fig (2)

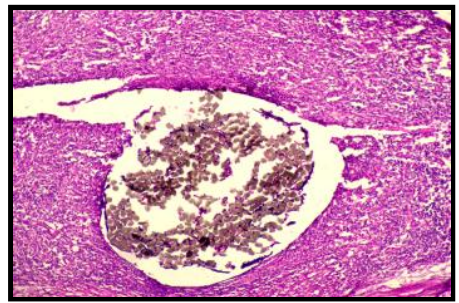

Fig (5)

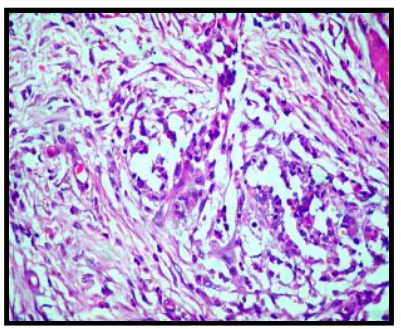

Fig (8)

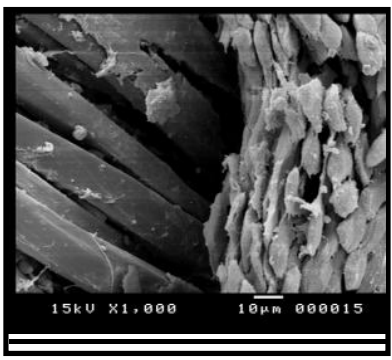

Fig (11)
Fig (3)

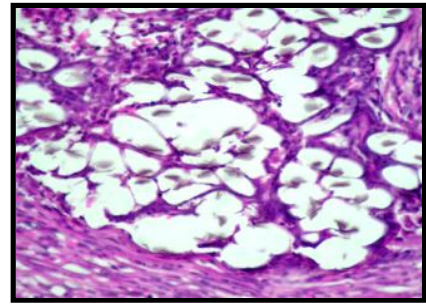

Fig (6)

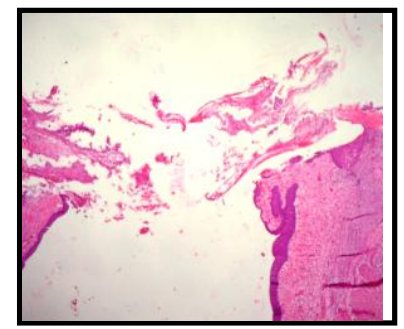

Fig (9)

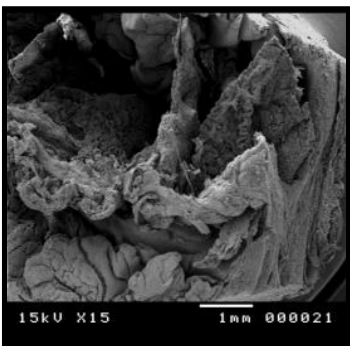

Fig (12)

Fig. 1: Lateral radiographic examination (urethrocystography) three weeks after closure of U.B with cat gut, normally distended bladder. 
Fig. 2: Urethrocystography three days after cystorrhaphy with super glue. leakage of contrast media from the U.B into the abdominal cavity

Fig. 3: Severe adhesion between the urinary bladder and omentum after two weeks by using catgut.

Fig. 4: L.M of U.B at 2nd week postoperatively showing the epithelial covering formed by more than one epithelial layer with papillary projection or polypoid formation. H\&E stain. Mag, 40.

Fig. 5: L.M of U.B at $3^{\text {rd }}$ week showing silk surrounded by moderate collagenous c.t and in other areas the s.m surrounded by extravasated blood and leukocytic cell reaction. H\&E stain. Mag, 100

Fig. 6: L.M of U.B at $3^{\text {rd }}$ week showing collagenous fibrous c.t surrounding the remnant of the suture fibers (polyglycolic acid). H\&E stain. Mag, 400.

Fig. 7: L.M of U.B at $3^{\text {rd }}$ week showing marked hydrolysis of vicryl fibers. H\&E stain. Mag, 100.

Fig. 8: L.M of U.B at $3^{\text {rd }}$ week showing polysorb completely absorbed and replaced by c.t and some macrophages. H\&E stain. Mag, 400.

Fig. 9: L.M of U.B at $3^{\text {rd }}$ week showing The epithelium at the edges proliferated forming transitional type but not covering the adhesive material with presence of Fibroblastic cell proliferation and macrophage at adhered site. H\&E stain. Mag, 40.

Fig. 10: S.E.M of bladder mucosa sutured with cat gut showing the transitional epithelium at line of incision after 3 weeks post operatively more or less normal appearance.

Fig. 11: S.E.M showing the epithelium neighboring the silk, swollen and separated from each other at three weeks postoperatively.

Fig. 12: S.E.M of the mucosal surface after 3 weeks showing the tissue adhesive filling the incision gaps in between wound edges.

\section{DISCUSSION}

The main aim of using suture materials is to approximate the wound edges to enhance the healing process. All the suture materials are considered as a foreign bodies when they are used inside the urinary tract. (Case, Glenn and Postlethwait 1976; Bondo-Simoes, Collaco, Veronese, Ribas and Flores, 1998).

The suture materials which are used inside the urinary tract should have some properties as to be non allergic, resist infection, maintain its tensile strength for a long period and should be completely absorbed with minimal inflammatory reaction (Case et al., 1976; Edlich, Rodeheaver and Thacker 1987 and Seifman et al., 2002). 
The healing process in our study in group 1, 2,3,4,5 begin to be observed in the three layers of the urinary bladder at the site of the incision with high degree at the end of the $1^{\text {st }}$ week postoperatively. This process of healing appeared in the form of leukocytic cell reaction and fibroplastic cell proliferation. These process of healing reach its maximum activity at the end of the $2^{\text {nd }}$ week postoperatively where the reaction mostly fibrocytic cell proliferation. At the end of the $3^{\text {rd }}$ week postoperatively the line of the incisions were completely regenerated in the mucosal layer by transitional epithelium and in the muscular layer by collagenous connective tissue formation. These findings were in agreement with those described by (Hastings and Van winkle, 1972; Peacock, 1984). Concerning the point of absorption of the suture materials and tissue reaction surrounding it in each group. In case of catgut, the suture material are present at $1^{\text {st }}, 2^{\text {nd }}$ and $3^{\text {rd }}$ week postoperatively but it become contracted or shrinkage. The reaction surrounding it begins by presence of polymorphnuclear cells and fibroplastic proliferation with oedema and hyperaemia of the vasculature. Starting from the end of $1^{\text {st }}$ week toward the end of the experiment, the collagenous connective tissue formation was inceased with decrease of leukocytic cells reaction. These results were in agremment with those found by Case, et al. (1976). Moreover Youssef and Bayoumi, (1991) concluded that, the tissue reaction was mild toward catgut after studying tissue reaction toward the coated polyglycolic acid sutures in comparison to catgut sutures for urinary bladder closure.

In case of polyglycolic acid, suture material are present at $1^{\text {st }}, 2^{\text {nd }}$ and $3^{\text {rd }}$ week postoperatively with marked or prominent hydrolysis of its fibers. This hydrolysis reach its peak at $3^{\text {rd }}$ week where there are remnants of the suture material still present. The tissue reaction surrounding the suture material appeared in the form of heavily leukocytic cell reaction and fibrocytic cell proliferation with presence of RBC with invasion of reacting cells in between the fibers. The reaction reach its maximum at $3^{\text {rd }}$ week postoperatively where there are collagenous connective tissue are formed. These finding were in agreement with those stated by Postlethwait, (1970) and Bartone et al. (1973). During light and microscopical study on polyglycolic acid in the urinary tract.

Our observation showed that there is point of similarity between the vicryl and polysorb group. The suture materials in both of them are present till the end of the experiment with marked hydrolysis of its fibers mainly at $3^{\text {rd }}$ week. The reaction was represent at $1^{\text {st }}$ week postoperatively in the form of polymorph nuclear cellular infiltration and some of macrophage and RBC that surrounded the suture material. Also there is dense fibrous tissue of collagenous type surrounding the suture material as 
well as at the line of incision at $3^{\text {rd }}$ week. But there are some sites in case of polysorb group showing deposition of calcium on the suture material. Our results about vicryl was similar to that achieved by Bartone et al. (1977) during two weeks, but at $3^{\text {rd }}$ week postoperatively there are small epithelial cysts were observed in their study and increase in its size with time and they considered it that may be act as reservoir for infection.

Concerning healing process, silk was not absorbed and it is the only suture material that was observed grossly from mucosa. Moreover there was no change in its position at $1^{\text {st }}, 2^{\text {nd }}$ and $3^{\text {rd }}$ week postoperatively. The reaction was observed in the form of leukocytic cell infiltration with extravasated blood at $1^{\text {st }}$ week. Also at the end of the experiment there were degenerative changes in the regenerated epithelium with moderate collagenous connective tissue (c.t) and few leukocytic infiltrations. There were small pockets or cysts observed in the mucosa which may be act as a predisposing factor for stone formation. So use of non absorbable suture material for closure of wounds in the urinary tract was not preferable. The obtained results agreed with that reported by Karen, (2000) who stated that, there is no need to use non absorbable suture materials in urinary bladder surgery. Because non absorbable suture materials penetrate the mucosa, they provide a nidus for urinary calculi formation.

In case of group(6), the adhesive material was observed without any changes at $1^{\text {st }}, 2^{\text {nd }}$ and $3^{\text {rd }}$ week postoperatively. The tissue adhesive material could be observed grossly and by Scanning electon microscope in the mucosal layer as irregular mass filling gaps in between wound edges. Microscopically there were leukocytic cell reactions mixed with extravasated RBC at $1^{\text {st }}$ and $2^{\text {nd }}$ week postoperatively. But at $3^{\text {rd }}$ week, the regenerated epithelium was proliferated but not covered the adhesive material with Fibroblastic cell proliferation with presence of macrophage cells at the site of adhesion with serosal surface. Because there was no healing process occur in the mucosal and muscularis layers and partially healing in the serosal layer during the experimental study. The obtained results not recommend the use of Methyl-2-cyanoacrylate tissue adhesive for closure of cystotomy incision in dogs.

In agreement with our findings, Cooper, and Falb, (1968); Vargas, Starr, and Cooper, (1978); Holmes, James, and Whitfield, (1992) reported that, most previous applications of tissue adhesives in the urinary tract have failed due to infection, encrustation or lack of tensile strength. Yoho, Drach and Koletsky, (1964) added that, when Methyl-2-cyanoacrylate was tested for closure of 3-cm-long cystotomies in dogs, but its use was associated with significant postoperative urinary leakage and calculus formation. Because of the previous concerns about tissue reaction, as well 
as some concerns over the potential carcinogenicity of the earlier compounds, cyanoacrylate adhesives have not yet been approved for internal use. These earlier forms of cyanoacrylate were non-absorbable, and moreover, were purported to be carcinogenic (Giunta, and Shklar, 1972).

\section{REFERENCES}

Bartone, FF.; Paul J. Gardner and James C. Hutson (1977): Polyglactine 910 suture in the urinary tract. Urology/ Volume IX, Number 5, 521-525.

Bartone, FF. and Gardner, PJ. (1973): Polyglycolic acid suture in the urinary tract. Alight and electron microscopic study. Urology 2: 43-46.

Bondo-Simoes, M.L.P.; Collaco, L.M.; Veronese, C.; Ribas, M.M. and Flores, S.N. (1998): Behavior of chromed catgut and polyglecaprone 25 sutures in the urinary bladder of rats, with special reference to stone formation. Acta Cir. Bras.13 (1): 26-29.

Case, GD.; Glenn, JF. and Postlethwait, RW. (1976): Comparison of absorbable sutures in urinary bladder. Urology. $1976 \mathrm{Feb} ;$ 7(2): $165-8$.

Cooper, C.N. and Falb, R.D. (1968): Surgical adhesives. Ann N Y Acad Sci, 146: 214.

Edlich, RF.; Rodeheaver, GT. and Thacker, JG. (1987): Considerations in the choice of sutures for wound closure of the genitourinary tract. J Urol. 137(3): 373-9.

Giunta, J. and Shklar, G. (1972): Studies on tongue carcinogenesis in rats using DMBA with and without cyanoacrylate adhesive. Arch. Oral. Biol. 17: 617.

Hastings, C.; Van Winkle, W.; Barker, E.; Hines, D. and Nichols, W. (1975): Effect of suture material on healing wounds of the bladder. Surg Gynecol Obetet 140: 933-937.

Hastings, JC. and Van Winkle, W.Jr. (1972): Considerations in the choice of suture material for various tissues. Surg Gynecol Obstet 135: 113.

Holmes, S.A.; James, M. and Whitfield, H.N. (1992): Potential use of tissue adhesive in urinary tract surgery. Br J Urol, 69: 647.

Karen K. Cornell (2000): Cystotomy, Partial Cystectomy, and Tube Cystostomy. Clinical Techniques in Small Animal Practice, Vol. 15, and No 1: pp 11-16. 
PAL, K.M.I. (1998): Urinary bladder wall repair: What suture to use? British Journal of urology, 82, 196-198.

Peacock, E.E. (1984): Wound Repair. Third ed., W.B. Saunders, Philadelphia, 1-37, 105-118, 476-478.

Samy, M.T.; Bolbol, A.E.; Bayoumy, A.H. and Moustafa, A. (1986): Non suture repair of the urinary bladder in dogs. $2^{\text {nd }}$ Sci. Congr., Fac. Vet. Med., Assiut.,Vol. 16 No. 32.

Seifman, BD.; Rubin, MA.; Williams, AL. and et al. (2002): Use of absorbable cyanoacrylate glue to repair an open cystotomy. J Urol; 167: 1872-1875.

Switzer, E.F.; Dinsmore, R.C. and North, J.H. Jr. (2003): Subcuticular closure versus Dermabond: A prospective randomized trial. Am. Surg. 69: 434.

Vargas, A.D.; Starr, A. and Cooper, F.F. (1978): Experimental use of fluoroalkyl cyanoacrylate in ureteral anastomosis. Invest Urol, 15: 416.

Vinters, H.V.; Galil, K.A.; Lundie, M.J. and Kaufmann, J.C. (1985): The histotoxicity of cyanoacrylates. A selective review. Neuroradiology 27: 279.

Yoho, A.V.; Drach, G.; Koletsky, S. and et al. (1964): Experimental evaluation of tissue adhesives in urogenital surgery. J. Urol, 92: 56-59.

Youssef, H.A. and Bayoumi, A.H. (1991): Evaluation of coated polyglycolic acid sutures (Dexon plus) for urinary bladder closure. Assiut Vet. Med. J., 26 (51): 269-275. 


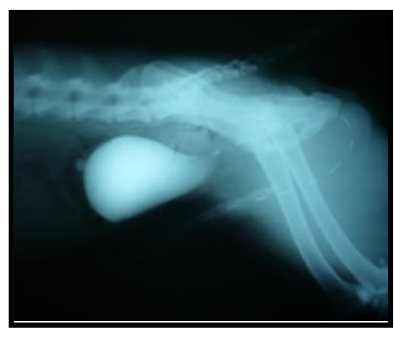

Fig (1)

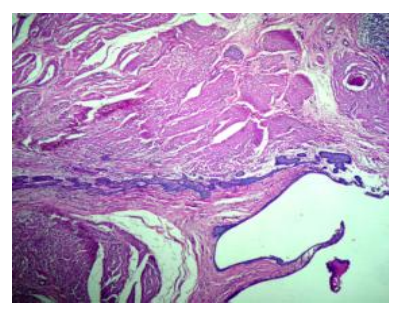

Fig (4)

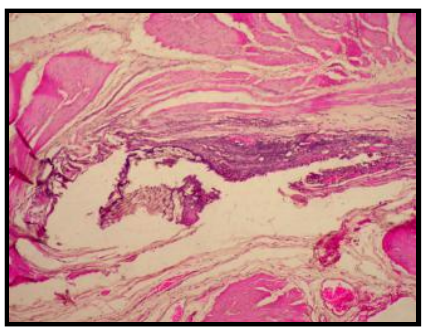

Fig (7)

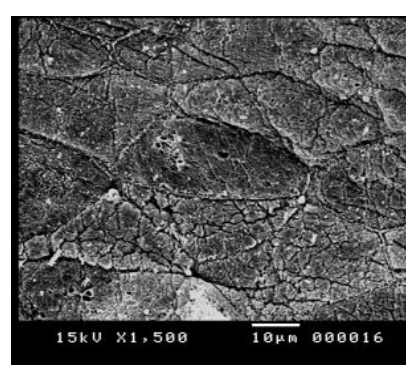

Fig (10)

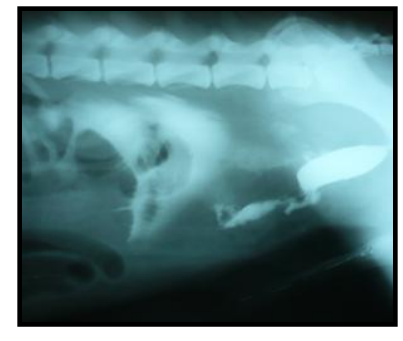

Fig (2)

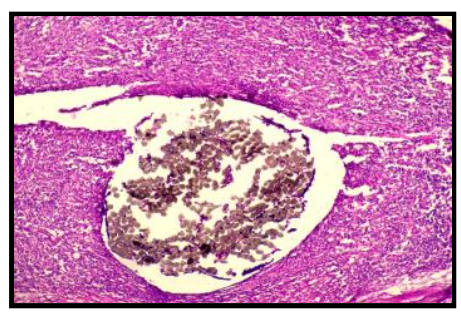

Fig (5)

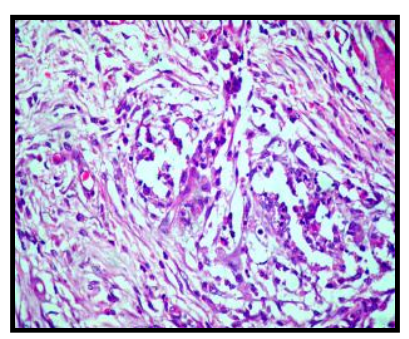

Fig (8)

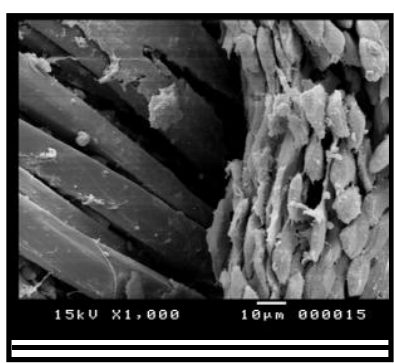

Fig (11)

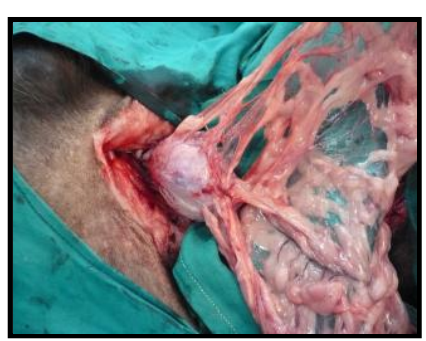

Fig (3)

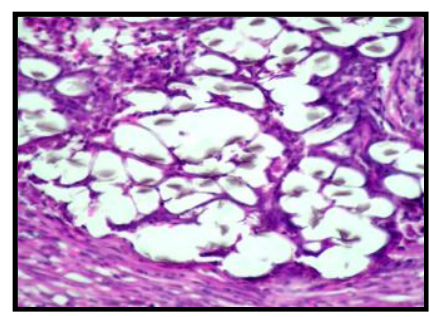

Fig (6)

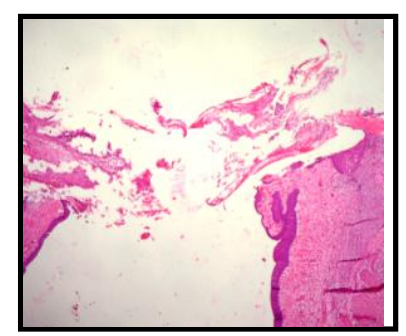

Fig (9)

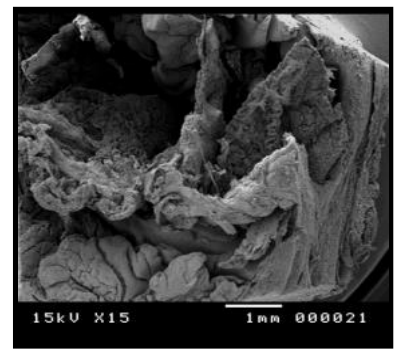

Fig (12) 